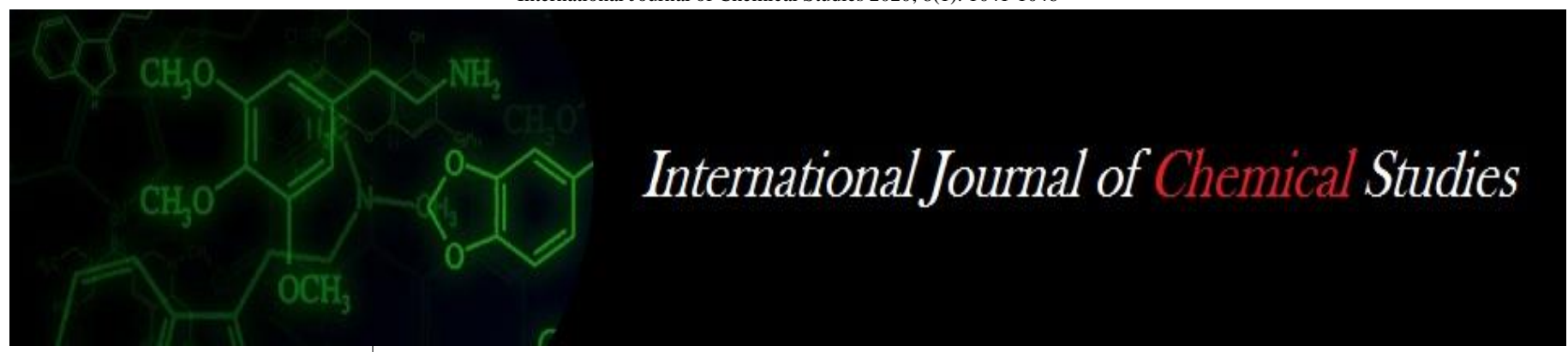

P-ISSN: 2349-8528

E-ISSN: 2321-4902

IJCS 2020; 8(1): 1041-1046

(C) 2020 IJCS

Received: 09-11-2019

Accepted: 13-12-2019

\section{Bobade}

Ph.D. Scholar, Department of Livestock production and Management, College of Veterinary Science \& A.H., CGKV, Anjora, Durg, Chattishgarh, India

\section{VN Khune}

Assistant Professor, Department of

Livestock production and Management, College of Veterinary Science \& A.H., CGKV, Anjora, Durg, Chattishgarh, India

\section{Sharad Mishra}

Professor and Head, Department of Livestock production and Management, College of Veterinary Science \& A.H. CGKV, Anjora, Durg, Chattishgarh, India

\section{Ashutosh Dubey}

Ph.D. Scholar, Department of Livestock production and Management, College of Veterinary Science \& A.H., CGKV , Anjora, Durg, Chattishgarh, India

Aayush Yadav

Ph.D. Scholar, Department of Livestoc production and Management, College of Veterinary Science \& A.H., CGKV Anjora, Durg, Chattishgarh, India

Anupam Soni

M.V.Sc. Scholar, Department of

Livestock production and Management,

College of Veterinary Science \& A.H.,

CGKV, Anjora, Durg, Chattishgarh,

India

\section{Sudheer Bhagat}

M.V.Sc. Scholar, Department of

Livestock production and Management, College of Veterinary Science \& A.H., CGKV, Anjora, Durg, Chattishgarh, India

Subhrajit Das

M.V.Sc. Scholar, Department of Livestock production and Management, College of Veterinary Science \& A.H., CGKV, Anjora, Durg, Chattishgarh, India

Kundan Krishnan

M.V.Sc. Scholar, Department of Animal Nutrition, College of Veterinary Science \& A.H., CGKV, Anjora, Durg. Chattishgarh, India

\section{Corresponding Author:}

Anupam Soni

M.V.Sc. Scholar, Department of

Livestock production and

Management, College of

Veterinary Science \& A.H.

CGKV, Anjora, Durg,

Chattishgarh, India

\title{
New age dairy farming: Precision dairy farming (PDF): A review
}

\section{Bobade, VN Khune, Sharad Mishra, Ashutosh Dubey, Aayush Yadav, Anupam Soni, Sudheer Bhagat, Subhrajit Das and Kundan Krishnan}

\author{
DOI: https://doi.org/10.22271/chemi.2020.v8.i1n.8386
}

\begin{abstract}
Dairy farming is a class of agriculture for long term production of milk, which is processed for eventual sale of a dairy product. Dairy farming from being 'traditional family run businesses' today, has grown hugely to an organized dairy industry with technological specializations in every part of the process. Affluent farmers are seeking to establish dairying units on a commercial level, with a big herd size of 30 50 animals and modern machinery. These large commercial farms are required to cope with a growing population, higher incomes, increasing health consciousness, and the consequent explosion in demand for pouch milk and value-added products across the country. Thus, farmers are shifting towards adopting modern dairy farming techniques in order to increase their production. Whether it is single-cow farms in India or commercial dairies, the dairy industry is under pressure in light of changing market forces and consumer preferences. A recent ban on selling cows for slaughter, dairy farmers are less likely to expand their herds since there is no market for cows that can no longer produce milk. Further, dairy farmers are looking for higher levels of quality, transparency, and consistency in their supply chains. Adopting the Precision Dairy Farming is best approach to increase the individual animal capacity and performance to maximize the profit and minimizes the production cost.
\end{abstract}

Keywords: Dairy, maximize, machinery, technology

\section{Introduction}

The Indian dairy market was valued at USD 5.4 billion, in the year 2010, which rose to USD 11.8 billion in the year 2015. By the year 2020 the dairy industry market in India is expected to be valued at USD 22.5 billion based on the projections and past trends. Dairy farming is very important and has become very popular these days in terms of profit margin. Dairy farming has evolved greatly over blast few decades. Advancement in technology have allowed farmers to improve everyday quality of life of their herds. At the same time dairy farmers have to take into account consumers demands and an acceptable environmental impact of livestock production ${ }^{[3]}$. The decision making in dairy farming has also been changed dramatically considering the quality assurance, natural foods, pathogen-free food, zoonosis, minimizing the use of medicine and animal care ${ }^{[18]}$. Changes in dairy farm operations can be attributed to tremendous technological progress in genetics, nutrition, reproduction, disease control and livestock management. As the technological advances continue, farmers are now in position to measure and analyze the vast array of individual animal's activities that were not possible previously or were time consuming. Philpot (2003) ${ }^{[12]}$ apprehended these changes in describing the Precision Dairy Farming as "technological marvels".

Precision dairy farming is the use of technologies to optimize the contribution of from each animal by adopting the 'per animal' approach. The trend toward group management may be reversed with Precision Dairy Farming as the focus returns to individual cows through the use of technologies ${ }^{[16]}$.

Precision Dairy Farming provides information. What to do with that information is next step. By proper processing of this information in combination with decision support systems, dairy farm managers can improve the health and welfare of the their herd effectively and it will be helpful in increasing the efficiency and improving the quality of end product. 


\section{What is precision dairy farming (PDF)?}

According to Schulze et al., (2007) ${ }^{[16]}$ a PDF system is constructed of the following components: a sensor that generates data, a model that gives a physiological interpretation of the data, a management decision making process and finally decision execution. The PDF systems can be divided into two categories: those used for diagnostic and those used for management and the same sensor can serve both categories.

Bewley (2010) ${ }^{[4]}$ described PDF as 'the use of technologies to measure physiological, behavioural, and production indicators on individual animals to improve management strategies and farm performance'. He also states that the objectives are to maximize individual animal potential while facilitating early disease detection and minimizing medication use.

Eastwood et al (2012) ${ }^{[6]}$ defined Precision Dairy Farming as "the use of information technologies for assessment of finescale animal and physical resource variability aimed at improved management strategies for optimizing economic, social and environmental farm performance".

The main objectives of Precision Dairy Farming are maximizing individual animal potential, early detection of disease, and minimizing the use of medication through preventive health measures.

Technology in dairy sector is playing a huge role in producing high yields and it is making cows happy and healthier. Be it boosting the production of milk or monitoring the herds by embracing the digital trends dairy farmers are making a great business throughout the world. However, in India, it is expected that digitalization will cover the most complex regions of dairy farming to offer seamless profits by overcoming the Indian dairy business difficulties and framework.

Using technologies to monitor farm animals is useful as long as technologies continuously monitor parameters, reliably observe behaviors, and accurately describe behaviors with reliable algorithms ${ }^{[3]}$. Making improvements in work-routine efficiency reduces time required to complete a task, employee stress, and provides the operators time to focus on other areas [15]. This contrasts traditional dairy production systems where product quality depends almost entirely on the skill, experience, and subjective assessments of the individual producer or worker ${ }^{[8]}$.

Technology adoption can improve or maintain animal welfare on dairy farms and help to improve public perception by demonstrating the dairy community's commitment to developing welfare improvement strategies [14]. In addition to improving public perception of cattle welfare, technologies accurately monitor individual animals and farms, which can increase animal production efficiency and decrease the environmental impact of livestock production, thereby also improving public perception ${ }^{[9]}$.

\section{Precision dairy farming technology use}

Modern dairy farming is constantly searching for new innovations and the latest can boost milk yields, enhance milk quality and reduce the costs associated with producing the white stuff. There are certain aspects of farm management which if handled through technology can reduce costs and make operations efficient. Some amazing gadgets used by some dairy farmers across the world, for making a profitable business. Dairy farmers use many precision technologies to monitor many parameters pertaining to their cattle and operations. Parameters monitored by these technologies include daily milk yield, milk components, step number, temperature (in various places and forms on and within the cow), milk conductivity, automatic estrus detection monitors, and daily body weight measurements ${ }^{[4]}$. In addition to the parameters already monitored, many other parameters have also been proposed such as jaw movements, ruminal $\mathrm{pH}$, reticular contractions, heart rate, animal positioning and activity, vaginal mucus electrical resistance, feeding behavior, lying behavior, odor, glucose, acoustics, progesterone, individual milk components, color (as an indicator of cleanliness), infrared udder surface temperatures, and respiration rates. Dairy producers with the lowest costs tend to be those implementing innovative management techniques and technologies ${ }^{[17]}$.

\section{Ideal PDF technology}

- Explains an underlying biological process

- Can be translated to a meaningful action

- Low-cost

- Flexible, robust, reliable

- Information readily available to farmer

- Farmer involved as a co-developer at all stages of development, not just beta-testing

- Commercial demonstrations

- Continuous improvement and feedback loops

\section{Currently used technologies in precision dairy farming}

The list of precision dairy farming technologies used for animal status monitoring and management continues to grow. Because of rapid development of new technologies and supporting applications, precision dairy farming technologies are increasingly more feasible. Many precision dairy farming technologies are already being utilized by dairy producers are: Electronic (radio frequency) identification systems and associated management software, Automatic body condition scoring, Automatic recording devices (rumen temperature, pressure, $\mathrm{pH}$ ) by electronic rumen bolus, Robotic milking systems - daily milk yield recording, milk component monitoring (such as fat, protein and SCC), daily body weight gain measurement, Robotic calf-feeding systems, Pedometers for heat detection, for health monitoring i.e. measuring lying time and standing bouts, Milk analyzer, Parturition sensors, Milk conductivity indicators.

Location of engineered devices for in situ data collection in a cow: (1) ear tag (2) halter (3) neck collar with counterweight (4) reticulo-rumen bolus (in reticulum) (5) rear leg pedometer (6) upper tail ring (7) tail head inject (8) vaginal bolus [5]

Other theoretical precision dairy farming technologies have been proposed to measure jaw movements, reticular contractions, heart rate, animal positioning and activity (to compare low activity to high activity where low activity may indicate a sick cow or a cow lying down), vaginal mucus electrical resistance, feeding behavior, odour, glucose, acoustics, progesterone, individual milk components, colour (as an indicator of cleanliness) and respiration rates. Further in the future the remote sensing of cow condition, GPS based cow tracking in fenceless farms may be included in commercially available precision dairying technologies. Some of these technologies are discussed as follows:

\section{Electronic (radio frequency) identification systems}

Electronic identification (EID) systems have provided a technological approach to the previously intuitive process of individual cow management. In 2000 the National Livestock Identification Scheme (NLIS) made the use of radio- 
frequency identification (RFID) tags, these tags contains a microchip that can be read electronically in a fraction of a second by producers who have a suitable reader. Electronic identification systems provide accurate identification of cows and linked to pedigree, management events, treatment records, electronic milk meters, computer controlled feeding, automatic sorting and weighing, etc.

Radiofrequency tags can be used to record animal events such as heat detection, treatments, calving interval, sire selection, etc. This can result in increased production and profitability by allowing better management of an individual cow's performance through the analysis of the collected data.

\section{Automatic body condition scoring}

Body condition scoring (BCS) is a method to evaluate fatness or thinness in cows that can be utilized to adjust dairy herd nutrition and improve the health of the cow. It is usually determined visually and manually by experienced experts to calculate body reserves and conducting body condition scoring and evaluate each animal. Roche et al 2009 [13] stressed out the significance of body condition score for animal. Automated Body Condition Scoring (BCS) through extraction of information from digital images has been demonstrated to be feasible; and commercial technologies are

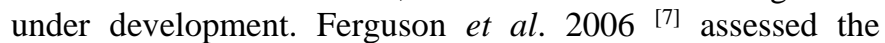
ability to assign a BCS to a dairy cow directly from digital photographs.

\section{Automatic recording devices (rumen temperature, pressure, $\mathbf{p H}$ )}

Determination of ruminal $\mathrm{pH}$, temperature and pressure in animals can be crucial to suppress the occurrence of health problems such as sub-acute rumen acidosis and bloat. Owen et al. $1998^{\text {[11] }}$ reported that rumen acidosis is a serious problem in dairy and feed-lot sectors, resulting in animal deaths, morbidity and diminished productivity.

a. Rumen temperature: Technology is being developed to continuously monitor intra-ruminal parameters such as temperature and $\mathrm{pH}$. Al-Zahal et al. $2008{ }^{[1]}$ reported that the relationship between rumen temperature and rumen $\mathrm{pH}$ may be an indicator in the diagnosis of SARA (Sub Acute Rumen Acidosis). A bolus containing a mote (temperature sensor, processor and radio) was placed in the rumen of a fistulated cow to monitor body temperature. Rumen temperature was measured every minute and stored in the internal buffer of the mote.

b. Rumen pressure: Rumen motility can be assessed by measuring changes in rumen pressure. Thus rumen pressure can be used to determine bloat in ruminants. There is not a lot of rumen pressure data for cattle. Therefore, the boluses would be a very useful tool for assessing the relationship between rumen pressures on bloat in cattle.

c. Rumen pH: Several important factors such as average ruminal $\mathrm{pH}$, the pattern of ruminal $\mathrm{pH}$ over time, duration of suboptimal ruminal $\mathrm{pH}$ and the variation in the pattern of ruminal $\mathrm{pH}$ can be processed by artificial intelligence or other advanced computational programs to evaluate the significance of ruminal acidosis in cattle performance as well as in defining the relations between intake and acidosis.

Monitoring ruminal fluid $\mathrm{pH}$ is a reliable method to determine acute acidosis or SARA. For research monitoring of rumen $\mathrm{pH}$, a permanent device in the rumen is required to continuously monitor rumen $\mathrm{pH}$ remotely without interfering with the normal behavior of the animal.

Currently available engineered devices for monitoring rumen function (all rumen bolus applications) are

1. eCow Devon (Exeter, UK)

2. San'Phone, Medria (Chateaubourg, FR)

3. Well Cow (Roslin, Midlothian, UK)

4. SmaXtec pH \& Temp Sensor, SmaXtec Animal Care (Graz, AT)

Robotic milking: Milking robot is a part of automatic milking system, having a sensor system to locate the position of the teats and a manipulator to attach the milking unit to the teat. Sensor systems for milking robots by identified several distinct sensing tasks Artmann, $1997^{[2]}$ :

i. Animal identification

ii. Teat location

iii. Monitoring Automatic Milking System functions.

iv. Ensuring proper machine function

v. Protecting people and animals from injury

vi. Measuring milk quantity and composition

vii. Monitoring other aspects of Animal health

\section{Advantages of robotic milking}

Milking by using robots has various advantages like:

- Economic benefit: Labor flexibility and not needing to manage hired labor were the biggest advantages reported by current users of robotic milkers.

- Increased milking frequency: Milking frequency may increase to three times per day, however typically 2.5 times per day is achieved. This may result in less stress on the udder and increased comfort for the cow, as on average less milk is stored. Higher frequency milking increases milk yield per cow.

- Management benefit: Management of the herd can be made more efficient. For a farmer who's never managed his cows properly the robot computer will force him to do so. It tells him about blood in the milk, conductivity, and yield per quarter.

- Cow health and welfare benefits: Producers reported an improvement in cow health and a reduction in instances of mastitis following the transition to robotic milking. This was attributed to less stress on the cows and to have better access to information on their cows.

Robotic calf feeding: Robotic calf feeding system consists of the following four parts:

i. The calf feeder unit that mixes milk replacer with water

ii. The processor for controlling the feeder and data processing

iii. The transponder around the neck of the calf for identification

iv. The milk feeding stall where the calf drinks the milk.

Automatic calf feeders consist of a self-contained unit that heats the water, dispenses a programmed amount of milk replacer, and mixes the milk replacer and water in a container from which the calf can suck it out via a nipple feeding station. Each calf as identified by their EID.

Calves start robotic feeding on day 10. It requires one day training them to use the feed stall. They stay there until they are weaned at approximately 45 days. Initially, each calf on the robotic feeder gets about 6 quarts of milk. That is increased to 9.5 quarts by 35 days. The feedings are spread out over the course of each day. The system only allows 
calves to be fed milk up to five times each day. Advantages are that calves are fed large amounts of milk replacer and so they gain weight rapidly. Their calves double their weight in 45 days.

\section{Pedometer for estrus detection}

Estrus behavior in dairy cattle is accompanied by increase in physical activity. Kiddy was the first to use leg mounted pedometers to determine whether physical activity related to estrous varied enough compared with non-estrual animal which will be a useful method for estrous detection in dairy farming.

Comparison among various statistical procedures that use pedeometry data in lactating dairy cows indicate that $70 \%$ of estrous period and $99 \%$ of non-estrual periods can be accurately predicted using currently available pedeometry systems. Lehrer et al. 1992 $2^{[10]}$ reported efficiency of visual observation at $45 \%$ and for pedometers at $78 \%$ to $96 \%$.

Currently available engineered devices for monitoring oestrus are as below.

\begin{tabular}{|c|c|}
\hline Oestrus activity behaviour & Device location \\
\hline 1. Cow Manager, Sens Oor, Agis Automatisering (Harmelen, NL) & Ear \\
\hline 2. Cow Alert, Ice Robotics (Edinburgh, Scotland, UK) & Neck or leg \\
\hline 3. Cow Scout, GEA (Düsseldorf, DE) & Neck \\
\hline 4. Qwes (Lely, NL) & Neck \\
\hline 5. Activity meter, De Laval (Tumba, SW) & Neck or leg \\
\hline 6. Silent Herdsman Afimilk (Kibbutz Afikim, IL) & Neck \\
\hline 7. Moo Monitor, Dairy Master (Tralee, IE) & Leg \\
\hline 8. Heat Phone, Medria (Chateaubourg, FR) & Tail head \\
\hline 9. Gyuho SaaS Fujitsu (Fukuoka, JP) & Neck \\
\hline 10. Heat Wath II, Cow Chips (Manalapan, NJ, US) & Leg \\
\hline 11. Heatime, EFS (Westmeath, IE) & Rumen bolus \\
\hline 12. Heat Seeker, BouMatic (Madison, WI, USA) & Harness reader and tail inject \\
\hline
\end{tabular}

Parturition sensors: Sensors fixed on pregnant animal Vaginal temperatures (VT) of cows were collected by a datalogging apparatus with a thermocouple sensor.

- Sense the change in body temperature - useful to save work and trouble at perinatal parturition of cattle.

- Predicting the onset of parturition is an important requirement and enables the rescue of newborn calves and mothers in difficult birthing situations.

- It has long been known that body temperatures decrease prior to parturition in cattle.

\section{Currently available engineered devices for monitoring calving behaviour are:}

1. Vel'Phone, Medria (Châteaubourg, FR): Vaginal temperature

2. iVET birth-monitoring (Papenburg, DE): Vaginal temperature

3. Moocall (Dublin, IE): Tail ring

\section{Potential benefits of precision dairy farming}

Benefits of Precision Dairy Farming technologies are increased efficiency, reduced costs, improved product quality, minimized adverse environmental impacts, and improved animal health and well-being. These technologies are likely to have the greatest impact in the areas of health, reproduction, and quality control. Benefits realized from summarizing data and reporting exceptions are anticipated to be higher for larger herds, where individual animal observation is more challenging and less likely to occur. A Precision Dairy Farming technology allows dairy producers to make more timely and informed decisions, resulting in improved productivity and profitability. Real time data can be used to monitor animals and create exception reports to identify meaningful deviations from the normal pattern. In many cases, dairy management and control activities can be automated. Alternatively, output from the system may provide a recommendation for the manager to interpret.

\section{Dairy farm tech startups}

From sensors and software to biotechnology, some dairy tech startups are working to improve safety and efficiency on the world's dairy farms.

1. Advanced animal diagnostics - US: Develops tools to diagnose livestock disease on the farm. The North Carolinabased company aims to help cut back on the number of antibiotics administered to livestock on farms. The technology uses the animal's immune system response to identify and determine the stage of infections, offering an alternative to blanket preventative antibiotic-administration, which is increasingly blamed for growing antibiotic resistance, while also saving traditional testing time and expense.

2. Cainthus (Ireland): It is an Irish startup focused on using computer vision and predictive imaging analysis to monitor the health and well-being of livestock. Cainthus uses various types of imaging equipment to monitor livestock operations while artificial intelligence and custom algorithms detect behavior in individual animals to monitor their health and alert the user when an action is required. The Cainthus system is able to detect food and water intake in individual animals as well as when the animals are in heat.

3. Connecterra (The Netherlands): It is a Dutch animal health monitoring technology company that manufactures wearable devices for dairy cows to monitor their health in real-time using machine learning and sensor technology. Dairy wearables are nothing new as cows have been wearing pedometers for at least 20 years. But the devices on the market today and previously, have been hardware technologies for the most part. In order to make use of the information coming from them, farmers and their advisors have had to analyze the data themselves. Connecterra is hoping to remove that burden using machine learning to interpret the data for the farmer, in the cloud. 
4. Consumer physics (Israel): Cargill Animal Nutrition is collaborating with Israeli startup Consumer Physics over a new technology platform for US dairy producers called Reveal. Reveal combines Consumer Physics' SCiO, a small handheld Near-Infrared (NIR) spectrometer, with Cargill's forage lab analysis platform, to provide dairy farmers with real-time analysis of their corn silage, haylage and dry hay on the farm to understand its content. This can help farmers to improve the diet of their herd and improve feeding efficiency.

5. Epi Biome (US): offers bacteriophage therapy, a macromolecular bacterial virus with a bullish disposition that seeks out and destroys specific strains of bacteria. Its platform can produce phage cocktails to treat mastitis in cows. Bovine mastitis, which infects cows' udders and renders their milk unfit for human consumption, is the primary reason to administer antibiotics in today's livestock industry. EpiBiome is developing alternatives to small-molecule antibiotics. The ultimate phage cocktail could be administered directly into the udder using a syringe.

6. Mastiline (Netherlands): develops and manufactures sensors and an automated monitoring system to detect the early signs of mastitis. The startup's sensors enable dairy farmers to detect mastitis at a subclinical level before visible signs of the disease manifest. It does so by detecting somatic cell counts, which indicate whether mastitis is present. The technology allows dairy farmers to reduce costs as a result of mastitis prevention, reduce the use of antibiotics, increase overall herd yield, and get better pricing for good quality milk with a low somatic cell count.

7. Silent herdsman (Israel): It has developed a neck-collar monitoring system used to detect estrus and health problems in dairy cows. The device, which is currently used in hundreds of dairy farms throughout Europe, is intended to help dairy farmers spend less time visually observing their herd and more time taking proactive steps to treat emerging problems. To maintain milk production, dairy cows must be bred regularly. Determining when the cow is ready to breed or whether health problems have arisen that might impact her breeding capability is critical to keeping operations flowing smoothly. Israeli dairy farm management technology provider Afi milk acquired Silent Herdsman in 2016.

8. Stell Apps (India): offers data collection and analytics to every piece of the dairy supply chain with the aim of improving the productivity, and quality of milk, and producing transparent data both for and about the Indian dairy industry. The full stack includes 26 different sensors across the chain. On the farms, wearable devices collect animal specific data from the cows and buffalos. At the dairy collection sites, quality analysis sensors measure fat content to assess the quality of the milk to help with pricing. These records are sent automatically to the dairy company's headquarters and the farmer's phone via SMS quantifying the quality of milk removes the guesswork and variability out of pricing. In the cold chain, sensors monitor the conditions to give dairy collection companies more control over the quality of their product and enable to produce more transparent information for their end customer. Stell Apps is backed by Blume Ventures, Binny Bansal, cofounder of Flipkart, Venture Highway and India-focused agtech VC Omnivore Partners.
9. TL Biolabs (US): offers 15 genomic tests for beef and dairy cattle, and the software needed to analyze the results. The company's microarray testing is designed to help farmers predict every heritable trait in cattle from birth including health, productivity, and fertility. This can enable them to make more data-driven breeding and farm management decisions, such as which calves to keep or sell, and which bulls to breed with which cows.

\section{Current status of precision dairy farming}

Despite widespread availability, adoption of these technologies in the dairy industry has been relatively slow. The majority of information management systems available and utilized by many dairy producers have analytical capabilities that are underutilized. In practicality, their use is often limited to creating production tables, attention lists, and working schedules. Perceived economic returns from investing in a new technology are likely the main factor influencing Precision Dairy Farming technology adoption. Additional factors impacting technology adoption include degree of impact on resources used in the production process, level of management needed to implement the technology, risk associated with the technology, institutional constraints, producer goals and motivations, and having an interest in a specific technology. The most progressive producers will adopt those new technologies that appear to be profitable.

In India, the future of dairy farming with the help of technology is quite bright. Government is encouraging dairy farmers to use technology in their process. Dairy tech startups has coming up with advanced technologies which will help the Indian Dairy farmers with the three step solution viz; going into rural communities through fully equipped mobile vans, leveraging data analytics through an app to offer demand-led-extension training to farmers and developing rural youth and women as village entrepreneurs. Hundreds of thousands of Indian cows are constantly transmitting information about their health directly to their farmers. These sensors deliver an array of information, including news of pregnancy, vaccination reminders, and even diet-change recommendations. Dairy officials can access the records through their Smartphone and act accordingly. If applied widely, this technology could considerably improve India's dairy farming practices and productivity. Setting up a network of internet of things (IoT) sensors that monitors health and fertility-related issues will improve cattle management, with technology helping to identify health deficits and ensure early treatment, besides navigating dry periods when cows don't lactate. Technologies for physiological monitoring of dairy cows have great potential to supplement the observations of skilled herd's persons, which is especially critical as more cows are managed by fewer skilled workers.

\section{Potential Limitations}

1. Information obtained from precision dairy farming technologies is only useful if it is interpreted and used effectively in decision making.

2. Slow adoption rate due to uncertain return on investment, high fixed costs of investment and information acquisition.

3. Animal ID may sometime read errors.

4. Equipment failure may occur because often they are sophisticated to handle, low temporal resolution, and require good visibility of the subjects. 
5. Data transfer error may be due to over-supply of data, and the time-consuming handling of software programme.

6. Lack of validated research results concerning the effects of application, high capital input and high costs.

7. Applicable to a restricted spatial area

\section{Conclusion}

Precision dairy farming is a new golden era of dairy industry. Precision Dairy Farming technologies provide tremendous opportunities for improvements in individual animal management on dairy farms. Combined, all devices will provide data that measures cow comfort, which can then be extrapolated to make changes in the dairy's facilities. Many progressive farms will incorporate precision dairy farming technologies into their daily management within the next 10 years, but not all dairies will adopt these technologies.

Precision dairy farming in India is in its infancy but there are numerous opportunities for adoption. A recent ban on selling cows for slaughter, dairy farmers are less likely to expand their herds since there is no market for cows that can no longer produce milk. Further, dairy farmers are looking for higher levels of quality, transparency, and consistency in their supply chains. Dairy tech startups has coming up with advanced technologies which will help the Indian Dairy farmers with the three step solution viz; going into rural communities through fully equipped mobile vans, leveraging data analytics through an app to offer demand-led-extension training to farmers and developing rural youth and women as village entrepreneurs.

\section{References}

1. Al-Zahal, Kebreab OE, France J, Froetschel M, McBride BW. Ruminal temperature may aid in the detection of subacute ruminal acidosis. J. Dairy Sci.2008; 91:202-207.

2. Artmann R. Sensor systems for milking robots. Comput Electron Agrci. 1997; 17:19-40.

3. Berckmans D. Precision livestock farming research. In proceedings of first European Conference on Precision Livestock Farming, Berlin, Germany, 2003.

4. Bewley J. Precision dairy farming: advanced analysis solutions for future profitability. In 'Proceedings of The First North American Conference on Precision Dairy Management', Toronto, Canada, 2010.

5. Caja G, Andreia Castro-Costa A, Knight $\mathrm{CH}$. Engineering to support wellbeing of dairy animals. Journal of Dairy Research. 2016; 83:136-147.

6. Eastwood C, Jago J. Precision dairy farming in New Zealand and Australia: A discussion document for transTasman collaboration between Dairy NZ and Dairy Australia. Report produced for Dairy NZ and Dairy Australia, 2012.

7. Ferguson JD, Azzaro G, Licitra. Body Condition Assessment Using Digital Images Journal of Dairy Science. 2006; 89(10):3833-3841.

8. Frost AR, Schofield CP, Beaulah SA, Mottram TT, Lines JA, Wathes CM. A review of livestock monitoring and the need for integrated systems. Computers and Electronics in Agriculture. 1997; 17(2):139-159.

9. Laca EA. Precision livestock production: tools and concepts. Revista Brasileira de Zootecnia. 2009; 38:123132.

10. Lehrer AR, Lewis GS, Aizinbud E. Estrous detection in cattle recent development. J Anim Reprod Sci. 1992; 28:355-361.
11. Owen FN, Secrist DS, Hill WJ, Gill DR. Acidosis in cattle: A review. J. Anim. Sci. 1998; 76:275-286.

12. Philpot WN. Role of technology in an evolving dairy industry. Pages 6-14 in 2003 Southeast Dairy Herd Management Conference, Macon, Georgia.

13. Roche JR, Friggens NC, Kay JK, Fisher MW, Stafford KJ, Berry DP. Invited review: Body condition score and its association with dairy cow productivity, health, and welfare. J Dairy Sci. 2009; 12:5769-801.

14. Rutten CJ, Velthuis AGJ, Steeneveld W, Hogeveen H. Invited review: Sensors to support health management on dairy farms. J. Dairy Sci. 2013; 96(4):1928-1952.

15. Schukken Y, Barkema H, Lam T, Zadoks R. Improving udder health on well managed farms: Mitigating the "perfect storm.". Pages 21-35 in Proc. International Conference on the Mastitis Control from Science to Practice. The Haque, 2008.

16. Schulze C, Spilke J, Lehner W. Data modeling for Precision Dairy Farming within the competitive field of operational and analytical tasks. Comput Electron Agric. 2007; 59:39-55.

17. Short SD. Characteristics and production costs of us dairy operations, 2004.

18. Singh SP, Ghosh S, Lakhani GP, Jain A, Roy B. Precision Dairy Farming: The Next Dairy Marvel. Journal of Veterinary Science and Technology. 2014; 5:164. 